\title{
O RITUAL COPIAR/COLAR NA ESCOLA: UMA ANÁLISE QUALI-QUANTITATIVA ${ }^{1}$
}

\section{The copy/past ritual at school: a quali-quantitative analysis}

\author{
Geová Bezerra GUIMARÃES \\ Instituto Federal do Amazonas - Campus Tabatinga \\ geova.bezerra@ifam.edu.br \\ https://orcid.org/0000-0001-9429-2531 \\ Sulemi Fabiano CAMPOS \\ Universidade Federal do Rio Grande do Norte \\ sulemifabiano@yahoo.com.br \\ https://orcid.org/000-0002-7212-0621
}

\begin{abstract}
RESUMO: Este artigo apresenta um levantamento feito em sala de aula para se verificar as características dos modos de escrita de alunos ao final do ensino fundamental. $\mathrm{O}$ objetivo é descrever e analisar os recursos linguístico-discursivos utilizados pelos alunos a partir de uma proposta de produção textual aplicada em sala de aula, sobretudo, no que se refere ao emprego das formas de remissão do discurso outro. Questionamos as maneiras pelas quais os alunos mobilizam as formas sintáticas do discurso relatado ao escrever textos. Para estudarmos esses recursos linguísticos, tomamos como aporte teórico o conceito de heterogeneidade enunciativa postulado por Authier-Revuz (1990; 2004) e os estudos de Maingueneau (2001)sobre discurso.Analisamos os dados qualitativo e quantitativamente, com foco na interpretação do que essas informações demonstram sobre os desafios de se ensinar a escrita na escola. Os dados indicam tendenciosamente que o ritual copiar/colar parece fazer parte do cotidiano das salas de aula, o que se coloca como um desafio no ensino e na aprendizagem da escrita.
\end{abstract}

PALAVRAS-CHAVE: Ensino da escrita; Discurso relatado; Ritual copiar/colar.

ABSTRACT: This article presents a survey done in the classroom to verify the characteristics of students' writing modes at the end of elementary school. The objective is to describe and analyze the linguistic-discursive resources used by students based on a proposal for textual production applied in the classroom, especially with regard to the

\footnotetext{
${ }^{1}$ Estudo desenvolvido para a elaboração de uma dissertação de mestrado intitulada Da reprodução à produção textual: a escrita na sala de aula, durante o curso de Mestrado Profissional em Letras (ProfLetras) na Universidade Federal do Rio Grande do Norte (UFRN), campus Natal/RN, defendida em 2 de dezembro de 2016.
} 
use of other forms of speech remission. We question the ways in which students mobilize the syntactic forms of the reported speech when writing texts. In order to study these linguistic resources, we take as theoretical support the concept of enunciative heterogeneity postulated by Authier-Revuz (1990; 2004) and Maingueneau's (2001) discourse studies.We analyzed the data qualitatively and quantitatively, focusing on the interpretation of what this information demonstrates about the challenges of teaching writing at school. The data tendentiously indicate that the copy/paste ritual seems to be part of the daily life of the classrooms, which poses a challenge in the teaching and learning of writing.

KEYWORDS: Teaching of writing; Reported speech; Copy/paste ritual.

\section{INTRODUÇÃO}

Este artigo apresenta um levantamento feito em sala de aula para se verificaras características dos modos de escrita de alunos ao final do ensino fundamental.Observamos uma disposição de o aluno reproduzir/reportar/citar/usurpar o discurso alheio pautado no "ritual copiar/colar", sem, contudo, referenciar o citado. Diante dessa problemática, pretendemos responder à seguinte pergunta de investigação: De que forma os alunos, no gerenciamento com outras vozes, mobilizam as formas sintáticas do discurso citado ao escrever seus textos? Analisamos os dados qualitativo e quantitativamente, com foco na interpretação do que essas informações demonstram sobre os desafios de se ensinar a escrita na escola.

A hipótese é a de que, diante de uma atividade comunicativa na qual terá de usar a aprendizagem da modalidade escrita, muitas vezes, regida por parâmetros, rica em dogmas pré-estabelecidos e valorizada socialmente, o aluno prefira representar sua voz tornandose uma espécie de procurador sem autorização e sem atribuir o devido crédito ao citado, isto é, toma como suas as palavras que lhe dão conforto ou das quais discorde, a depender da situação comunicativa ou, ainda, acreditamos que seja tão-somente dificuldade linguístico-discursiva em gerenciar o discurso alheio. Há indícios de que a palavra alheia soe como verdade e que possa ser utilizada conforme suas intenções comunicativas.

No primeiro momento, detalhamos os estudos científicos sobre o fenômeno linguístico de nossa investigação, as formas sintáticas do discurso relatado (em específico, o discurso direto, o discurso indireto, o discurso segundo e a ilha textual). Para estudarmos 
esses recursos linguísticos, tomamos como aporte teórico o conceito de heterogeneidade enunciativa postulado por Authier-Revuz (1990; 2004) e os estudos de Maingueneau (2001) sobre discurso. Neste artigo, tentamos relacionar e aplicar esses conceitos na análise de textos produzidos por alunos na escola.

No segundo ponto, fizemos um diagnóstico do conhecimento linguístico-discursivo já adquirido pelos alunos após alguns anos de escolaridade. Nesse viés, tabelamos as ocorrências linguísticas, indicadoras das marcas sintáticas do discurso relatado, em cada escopo textual, transcrevendo as configurações textuais para comprovar as evidências. Para além de apresentarmos os dados quantitativamente, tecemos um olhar crítico e analítico sobre o uso e os efeitos do fenômeno linguístico-discursivo em questão.

Para descrição e análise do corpus, mapeamos as ocorrências de reprodução literal do discurso de outrem, esboçadas em um quadro-resumo, quadro detalhado e transcrição de dois textos escritos, constituintes do corpus, para demonstrar a situação descrita; analisamos as marcas linguísticas que indiciem o uso de forma remissiva do discursooutro, quadro-resumo e quadro detalhado, exemplificando com a transcrição de dois textos escritos, constituintes do corpus, para apresentar o fenômeno detectado; averiguamos as formas de gerenciamento do discurso-outro predominantes nos textos observados na sequência anterior; destacamos, a partir do que fora observado, o(s) elemento(s) linguístico(s) que revela(m) resposta direta ao discurso de outrem, seguido de amostra de texto, comitente do corpus, para representação dessa evidência; e investigação de textos que apresentam "citação" sem marca linguística, isto é, o aluno se baseia nos textos lidos, mas os utiliza como "fonte implícita" e mostra de texto, retirado do corpus, para demonstrar essa estratégia linguística.

Por derradeiro, mas com o desejo de despertamos a emergência de outros estudos, tecemos nossas considerações finais a respeito do diagnóstico feito, destacando suas causas e consequências no ensino de língua portuguesa, em especial, ao da escrita. Este artigo não se propõe apenas como um documento a ser arquivado, pelo contrário, vem a público para que nele possa agir e provocar novas reflexões. 


\section{DISCURSO ALHEIO: FORMAS DE MOBILIZAÇÃO}

Diferentemente do que propõem Bakhtin e Volochínov (2014), que empregam o termo discurso citado para se referir às marcas linguísticas do discurso outro, materializadas na trama textual, Authier-Revuz (2008) prefere a expressão heterogeneidade $^{2}$. Essa preferência se justifica porque o termo citado poderia ter valoração de discursos vindouros, hipótese; e, tradicionalmente, o discurso citado tende a abordar, como fenômeno de remissão enunciativa, o Discurso Direto (DD), o Discurso Indireto (DI), o Discurso Indireto Livre (DIL) e variantes desses fenômenos, analisáveis em narrativas da cultura russa, tal qual Bakhtin e Volochínov (2014) desenvolveram no livro Marxismo e filosofia da linguagem, o que fez com que outras características não fossem consideradas nesses estudos, como, por exemplo, a Modalização em Discurso Segundo (MDS).

Já para Authier-Revuz (1990; 2004), ao se referir ao princípio da metadiscursividade (do discurso sobre o discurso), prefere representar a remissão do discurso-outro (RDO) optando pela expressão heterogeneidade enunciativa. Apesar de entendermos a distinção feita pela autora, não iremos optar por uma ou outra expressão, julgamos que, aqui, as duas poderão ser usadas, sem que haja sentido ambíguo ou controverso. Authier-Revuz $(1990 ; 2004)$ constrói esse saber e o propõe, a partir das contribuições provindas da Psicanálise freudiana, o consciente e o inconsciente, e do dialogismo bakhtiniano, um novo olhar para os fenômenos linguísticos: nasce assim o conceito de heterogeneidade enunciativa.

Essa percepção é dividida, segundo Authier-Revuz (2004), em dois campos: a "heterogeneidade constitutiva" e a "heterogeneidade mostrada". A primeira percepção elucida que todo enunciado linguístico (o dito), numa interação verbal, constitui-se pela hibridização de vozes, em outras palavras, o discurso sempre será atravessado por outros dizeres. A segunda concepção configura-se por meio de estruturas linguísticas sintáticas, que podem estar/ser ou não marcadas na tessitura textual. Isso prova que um discurso não é "homogêneo", puro, pois nele também outros discursos podem ser desvendados, ou seja, outras vozes podem ser reveladas no discurso/enunciado.

\footnotetext{
${ }^{2}$ Essa preferência é apresentada no artigo A representação do discurso outro: um campo multiplamente heterogêneo de Jacqueline Authier-Revuz (2008).
} 
Ainda para Authier-Revuz (2004), o discurso é constitutivo porque o sujeito se constitui na e pela linguagem (pela presença de "Outros" discursos) e heterogêneo, pois, no discurso, há sempre um "outro" discurso, velado ou não. Diante disso, nos parágrafos vindouros, pretendemos refletir sobre a heterogeneidade mostrada (o discurso citado, relatado), um fenômeno linguístico analisável, que se materializa nos textos sob a forma, geralmente, sintática, marcada na trama textual, com foco nas formas linguísticas indicadoras do discurso direto, discurso indireto, discurso segundo, ilha textual e discurso direto com "que".

Na sequência, construímos, a partir das contribuições de Authier-Revuz (2004) e Maingueneau (2001), um quadro-resumo com as características das formas sintáticas de remissão do discurso-outro. Vale salientar que esse quadro mostrará as características de cada um dos discursos relatados, o que não implica informar que haja variações desses exemplos, posto que poderão surgir formas decorrentes nos textos que compõem o corpus neste artigo. A saber:

Quadro 1: Tipos e características dos discursos relatados

\begin{tabular}{|l|l|}
\hline \multicolumn{1}{|c|}{ Tipos de discurso citado } & \multicolumn{1}{c|}{ Características } \\
\hline Discurso Direto (DD) & $\begin{array}{l}\text { O enunciador, supostamente, emprega as próprias palavras do } \\
\text { citado. }\end{array}$ \\
\hline Discurso Indireto (DI) & $\begin{array}{l}\text { O citante traduz o discurso citado (há diversas maneiras de essa } \\
\text { tradução ocorrer); } \\
\text { Preza-se pelo "conteúdo do pensamento" do citado. }\end{array}$ \\
\hline $\begin{array}{l}\text { Modalização em Discurso } \\
\text { Segundo (MDS) }\end{array}$ & $\begin{array}{l}\text { O enunciador exime-se do enunciado, apoiando-se em um outro } \\
\text { discurso (MAINGUENEAU, 2001); } \\
\text { O enunciador faz uso de modalizadores (Segundo X, Para X } \\
\text { etc.). }\end{array}$ \\
\hline Ilha Textual (IT) & $\begin{array}{l}\text { "O enunciador citante [isola] em itálico e entre aspas um } \\
\text { fragmento que, ao mesmo tempo, ele utiliza e menciona, } \\
\text { emprega e cita"; (MAINGUENEAU, 2001, p. 151); } \\
\text { É uma forma híbrida. }\end{array}$ \\
\hline $\begin{array}{l}\text { O Discurso Direto com “que”" } \\
\text { (DDq) }\end{array}$ & $\begin{array}{l}\text { Também é uma forma híbrida. } \\
\text { O citado apresenta características do DD, mas acompanhado de } \\
\text { "que". }\end{array}$ \\
\hline
\end{tabular}

Fonte: Maingueneau (2001).

Vejamos, agora, minuciosamente, cada um dos esquemas citados acima. O uso do discurso relatado é uma forma de se afastar, na enunciação, do próprio dizer. É o momento 
de abrir um espaço para outras vozes. Essa abertura pode ser feita, por exemplo, pela inserção do Discurso Direto (DD), Discurso Indireto (DI), Modalização em Discurso Segundo (MDS), Ilha Textual (IT) e Discurso Direto com “que” (DDq).

Sobre essas formas de reprodução do discurso-outro, comecemos, primeiramente, por caracterizar o discurso direto. Esse fenômeno discursivo

[...] não se contenta em eximir o enunciador de qualquer responsabilidade, mas ainda simula restituir as falas citadas e se caracteriza pelo fato de dissociar claramente as duas situações de enunciação: a do discurso citante $\mathrm{e}$ a do discurso citado (MAINGUENEAU, 2001, p. 140).

Ou seja,

[...] o discurso direto é uma forma - fundamentada na autonímia particularmente clara do distanciamento: o locutor-relator ali se apresenta como sendo, na parte citada, somente "a voz" que pronuncia palavras, dependendo, realmente de um outro ato de enunciação - outro par de interlocutores, outro tempo, etc. (AUTHIER-REVUZ, 2004, p.70).

Assim, ao optar pelo discurso direto (DD), por exemplo, o aluno torna-se o porta$v o z$ da(s) voz(es) do outro. A negociação nesse caso é feita de forma fidedigna (no sentido de encenar o discurso-outro). Abre-se, nessa escolha, um espaço para o discurso citado. $\mathrm{O}$ sujeito, produtor do texto, não apenas se afasta do seu próprio enunciado, mas também identifica, marca a voz citada. Nesse caso, os discursos são destituídos, separados, e essa marcação é feita de forma explícita no movimento de escrita.

Isso não quer dizer que o emprego do DD seja uma cópia real do discurso citado. Pelo contrário, “[...] o DD é apenas a encenação de uma fala atribuída a uma outra fonte de enunciação, e não é a cópia de uma fala 'real"” (MAINGUENEAU, 2001, p. 143). Dessa forma, ao optar pelo DD, o autor não reproduz fielmente o discurso citado, até porque o discurso já dito foi deslocado da sua situação comunicativa de produção primeira.

$\mathrm{O} \mathrm{DD}$, na verdade, é um resgate comunicativo - um discurso-outro repaginado pertencente a um determinado tempo e espaço (o que não dispensa de ser atravessado por outros dizeres também constitutivos e/ou explícitos). Assim, ao "ressurgir" em outro 
discurso não vai ao texto com toda legitimidade de outrora e, justamente por ter sido encenado em uma nova contextualização, atende a outra intenção discursiva.

Em contrapartida, ao movimentar a escrita por meio do DD, autor/falante procura "criar uma autenticidade", buscando a credibilidade do leitor/ouvinte; tende a "distanciarse", aderindo ou não o discurso citado; e tenta "mostrar-se objetivo". Maingueneau (2001), sobre isso, esclarece ainda que a escolha pelo DD decorre, principalmente, da intenção comunicativa do gênero discursivo (artigo de opinião, charge, tirinha, reportagem, notícia etc.), ou ainda parte das particularidades pertinentes a cada esfera social.

Sobre os três aspectos de escolha elencados pelo autor, detalharemos a seguir (usando as palavras do próprio autor, ou seja, via emprego do discurso direto) os possíveis motivos que levam a um autor/falante a marcar o discurso por meio do emprego do DD. Vejamos:

Criar autenticidade, indicando que as palavras relatadas são aquelas realmente proferidas;

Distanciar-se: seja porque o enunciador citante não adere ao que é dito e não quer misturar esse dito com aquilo que ele efetivamente assume; seja porque o enunciador quer explicitar, por intermédio do discurso direto, sua adesão respeitosa ao dito, fazendo ver o desnível entre palavras prestigiosas, irretocáveis e as suas próprias palavras (citação de autoridade);

Mostrar-se objetivo, sério (MAINGUENEAU, 2001, p. 142).

$\mathrm{O}$ primeiro ponto diz respeito à credibilidade que o autor/falante julga pretender ao empregar essa forma sintática. Espera, dessa forma, mostrar que o discurso citado é o próprio discurso citado (há, nesse caso, uma encenação, pois não há como acoplar nessa enunciação o aspecto temporal e espacial do discurso primeiro). O segundo fator destaca a falta de comprometimento do autor/falante (quer seja negar/repudiar, quer seja por aceitar/concordar) com o discurso citado. Há um distanciamento dos discursos citante e citado. É como que o autor/falante demonstrasse ao leitor/ouvinte o que pertence a ele e o que é do outro. Por fim, como deseja objetividade, ser claro, entendido, o autor/falante tenta demonstrar-se mais prático, faz-se compreensível, atribui sentido.

Na sequência, construiremos a percepção de Discurso Indireto (DI), confrontando esse modo dizer com o Discurso Direto (DD). Mostramos as particularidades de um e do 
outro, os pontos de convergência e divergência. Na verdade, essas formas embreantes, como rotula Maingueneau (2001), exercem papéis enunciativos particularmente paradoxais.

Enquanto no DD, não usamos as palavras como objeto do dizer, no DI, o citante usa palavras de sua propriedade para dizer o conteúdo do discurso do outro. O citante, então, interpreta o discurso tomado como fonte. Essa proposição já coloca o DD e o DI em situações interlocutivas distintas, opostas, o que coloca em xeque os exercícios escolares tão comuns em livros didáticos - de que passar um enunciado em DD para o DI e/ou viceversa seja um exercício reflexivo de linguagem. Essa construção é, numa enunciação dialógica, inatingível, justamente, porque, no DI, traduz-se o conteúdo do pensamento. Essas formas do discurso relatado não mantêm, portanto, relações enunciativas semelhantes, quanto ao conteúdo.

Nas palavras de Authier-Revuz (2004, p. 12), "No discurso indireto, o locutor se comporta como tradutor: fazendo uso de suas próprias palavras, ele remete a um outro como fonte do 'sentido' dos propósitos que ele relata". Se no DD, o citante cria um ponto de seção entre o seu discurso e o do citado, no DI, o citante diz o discurso-outro usando suas próprias palavras. O citante do DI tem na língua/linguagem uma gama de elementos linguísticos para dizer, ou melhor, traduzir o outro.

Assim como no DD, a escolha/seleção do verbo dicendi consiste num ato comunicativo, depende da intenção interlocutiva, isto é, "uma citação no discurso indireto perde sua autonomia enunciativa, tornando-se dependente do verbo introdutor" (MAINGUENEAU, 2001, p. 151).

Sintetizando as percepções do DD e DI, é imperativo destacar que

As formas direta e indireta do discurso reportado não têm sua origem no empréstimo de palavras dos outros, ou seja, do "falar com" as palavras de outros, sendo o seu modo de funcionamento aquele do falar de [da] fala do outro; o primeiro mostra as palavras dos outros, não usadas como objetos, enquanto o segundo faz uso de palavras próprias para falar do conteúdo da fala do outro (o uso de "suas próprias palavras" podendo sempre evidentemente se duplicar, sob a forma de discurso indireto como dizer não reportado, em uma menção interpretativamente marcada, do tipo como ele diz). (AUTHIER-REVUZ, 2000, p. 43). 
Essa autora, ainda, distingue, morfossintaticamente, essas formas de citar da seguinte forma: verbo dicendi + “...” para o Discurso Direto; verbo dicendi + que... para o Discurso Indireto.Assim, a estrutura do DD seria, textualmente, seguida de verbo de elocução, mais citação isolada por aspas, podendo também, aparecer outros elementos gráficos (dois-pontos, travessão); já no DI, a sintaxe constitui-se por verbo dicendi, acompanhado de conjunção subordinativa que, e da interpretação do discurso citado. A estrutura do DI é constituída por meio de uma oração subordinada substantiva objetiva direta.

No movimento de resgate da palavra de outrem também podemos nos apoiar em um discurso citado, de forma distante, por meio do emprego de modalizadores (Segundo X, Para X, De acordo com X etc.). Essa forma de enunciar sobre o enunciar é conhecida como modalização em discurso segundo (MDS). Inclusive quando comentamos a nossa própria enunciação também estamos empregando essa forma de remissão do discursooutro. A MDS consiste no emprego de "um discurso outro segundo o qual se fala", o que o distingue do DD e do DI, que é "um discurso outro do qual se fala" (AUTHIERREVUZ, 2008, p. 108).

$\mathrm{Na}$ verdade, ao optarmos por essa estratégia, a MDS, estamos também nos eximindo do discurso. A responsabilidade recai para outro enunciado, supostamente, por ser mais confiável socialmente. Esse recurso linguístico aproxima-se do discurso indireto, no entanto ao acoplar um modalizador antes do discurso enunciado, quase sempre uma paráfrase linguística ${ }^{3}$, parece que se está tentando dar mais credibilidade ao discurso citado.

Outra maneira de não se comprometer com o discurso, é utilizarmos as formas híbridas do discurso relatado. Há, nesse caso, pelo menos duas formas imbricadas. Esse cruzamento de discursos pode ocorrer de duas formas: ou por ilha textual (IT) ou pelo emprego do discurso direto com "que" (DDq).

A ilha textual consiste quando, na sintaxe do discurso citante, este isola graficamente (por aspas ou itálico) um discurso citado dentro do seu próprio discurso, ou seja, utiliza e menciona o outro, emprega e cita-o. Estruturalmente, essa forma de enunciar aproxima-se mais do DI, porém há elementos marcados na trama textual pertencentes ao

\footnotetext{
${ }^{3}$ Consultar a noção de paráfrase proposta por Fuchs (2012) no texto A paráfrase linguística - equivalência,
} 
discurso citado, configurando, assim, uma forma direta. Por isso, chama-se a ilha textual de uma forma híbrida do discurso relatado.

Outro fenômeno linguístico que se configura pelo hibridismo (DD/DI) é o discurso direto com "que" (DDq). É comum o emprego de uma estrutura que, aparentemente, possa ser marcado como DI (verbo dicendi + que), mas na verdade, trata-se do DD, já que o discurso citado é isolado por aspas (são as palavras do outro), determinando que não se atua como tradutor, pelo contrário, comporta-se como porta-voz. Sobre esse aspecto, é importante frisar que "o desenvolvimento desse tipo de discurso relatado é revelador de uma evolução da mídia" (MAINGUENEAU, 2001, p. 152). Nesse sentido, do mesmo modo que se distancia do sujeito tomado como interlocutor (via DD), "tentam 'colar-se' à sua linguagem e ao seu ponto de vista" ${ }^{\text {. }}$

Apresentamos as formas sintáticas indicadoras de vozes alheias, recorrendo aos pressupostos teóricos de Authier-Revuz (1990; 2004) e Maingueneau (2001). Para esses autores, a análise é feita em textos do domínio jornalístico francês. Aplicando esses modos de análise, neste artigo, pretendemos relacionar nossas críticas em textos escritos produzidos por alunos da rede pública. Assim, variantes dessas formas sintáticas de reprodução das vozes alheias podem aparecer nos escopos textuais.

\section{OS TEXTOS E OS EFEITOS DE SEUS DIZERES}

O corpus descrito e analisado neste artigo foi constituído em uma escola da rede pública, especificamente, numa turma de $9^{\circ}$ ano do ensino fundamental. A princípio, pretendemos averiguar os modos pelos quais os alunos mobilizam as formas sintáticas do discurso citado ao escrever textos. Descrevemos, na sequência, os dados gerados e em seguida apresentamos uma análise de cunho qualitativo e quantitativo. Para realização da proposta de produção escrita, lemos em sala de aula dois textos argumentativos: Maconha deve ser legalizada e traficantes da droga, anistiados ${ }^{5}$ (texto-fonte 1) do então Deputado Federal Jean Wyllys; e Legalização das drogas não é caminho para diminuir violência ${ }^{6}$

\footnotetext{
sinonímia ou reformulação?

${ }^{4}$ Loc. Cit.

5 Disponível em: <https://noticias.uol.com.br/opiniao/coluna/2014/04/30/maconha-deve-ser-legalizada-etraficantes-da-droga-anistiados.htm Acesso em: 30 mai. de 2016>. Acesso em: 30 jun. 2016.

${ }_{6}$ Disponível em: <http://noticias.uol.com.br/opiniao/coluna/2014/05/18/legalizacao-das-drogas-nao-e-
} 
(texto-fonte 1) do Deputado Federal Osmar Terra.

Comando da proposta de produção textual escrita

\begin{abstract}
PROPOSTA
Nos últimos anos, o debate em torno da legalização da maconha no Brasil retornou à mídia, dividindo opiniões nas redes sociais. Considerando a atualidade da temática, 0 site UOL abriu espaço para seus leitores publicarem textos sobre essa problemática. A partir de seus conhecimentos prévios sobre o tema e da leitura dos textos 1 e 2 , na condição de leitor desse veículo de informação, escreva um texto, defendendo um ponto de vista sobre a seguinte questão: Maconha: legalizar ou manter a proibição?
\end{abstract}

Orientações:

Ao escrever seu texto, use caneta esferográfica azul ou preta, escreva com letra legível e identifique-se apenas no local indicado. Assine o texto com o pseudônimo de Nazareno Duarte. Para construir sua argumentação, utilize as informações presentes nos dois textos.

Fonte: Guimarães (2016).

O corpus gerado a partir da proposta representa um total de 31 (trinta e uma) produções textuais escritas pelos alunos, enumerando-as de PED01 (Produção Textual Escrita Diagnóstica), correspondente ao Aluno 01, a PED31, pertencente ao Aluno 31.

Para orientar o leitor a identificar a que texto-fonte pertence o discurso reportado pelo aluno sem indicação de referência autoral, optamos por realçar os trechos "reproduzidos", seguindo os critérios: a tarja amarela indica que o recorte textual é oriundo do Texto-fonte 1; a tarja cinza mostra que "as palavras" pertencem ao Texto-fonte 2. A ausência de tarja indicará o discurso do próprio aluno, ou ainda, alguma reprodução feita de forma equivocada. As linhas não escritas foram suprimidas. Com a finalidade de apresentar uma distinção entre as configurações textuais tidas como fonte das tessituras textuais geradas por meio do exercício de produção escrita pelo aluno, iremos denominar este último por Texto-aluno, acompanhado do código identificador do aluno.

O fenômeno linguístico de nossa investigação são as formas sintáticas de remissão do discurso de outrem, de modo mais específico, o discurso citado direto (DCD), o discurso citado indireto (DCI), a modalização em discurso segundo (MDS) e a ilha textual (IT), essas últimas formas são marcas híbridas, podendo, dessa forma, comporem-se pelo DCD e/ou DCI ou ainda de uma estrutura variacional (muitas vezes, criada como um modo de reportar o discurso-outro, provavelmente, seguindo exemplos já conhecidos pelos

caminho-para-diminuir-violencia.htm>. Acesso em: 30 jun. 2016. 
alunos, oriundos ou dos próprios textos da coletânea, de textos da internet ou ainda de outros produtos textuais em que o fenômeno linguístico tenha se manifestado no escopo do texto).

Ainda para facilitar a descrição dos textos produzidos e deles refletir sobre os modos de escrita, criamos quadros demonstrativos, ressaltando os seguintes pontos: Exposição quantitativa e qualitativa, usando como corpus os 31 textos escritos, de acordo com a sequência: a) ocorrências de reprodução literal do discurso de outrem, quadroresumo e quadro detalhado, e transcrição de dois textos escritos gerados, constituintes do corpus, para demonstrar a situação descrita; b) marca linguística que indicie o uso de forma remissiva do discurso-outro, quadro-resumo e quadro detalhado, e transcrição de dois textos escritos, constituintes do corpus, para apresentar o fenômeno detectado; c) formas de gerenciamento do discurso-outro predominantes nos textos observados na sequência "b"; elemento(s) linguístico(s) que revela(m) resposta direta ao discurso de outrem e amostra de texto, comitente do corpus, para representação dessa evidência; e d) textos que apresentam "citação" sem marca linguística, isto é, o aluno se baseia nos textos lidos, mas os utiliza como "fonte implícita" e mostra de texto, retirado do corpus, para demonstrar essa estratégia linguística.

De posse dos textos escritos, constituintes do corpus, de início, dividimos e organizamos, quantitativamente, as ocorrências não marcadas e marcadas do modo de citar discurso alheio, consoante finalidade prevista na sequência "a". Por entendermos o texto como unidade de sentido, organizado em estruturas paragrafais, parafrásticas, consideramos que cada "recorte textual", destituída da supressão do todo ou de parte do período sintático ou do parágrafo, indica uma ocorrência de "reprodução".

$\mathrm{Na}$ análise dos dados gerados, um total 44 (quarenta e quatro) ocorrências linguísticas em que alunos demonstraram desconhecer ou tiveram inabilidade no que concerne à utilização das formas sintáticas do discurso relatado. Dos 31 (trinta e um) alunos que realizaram essa atividade, 14 (quatorze) demonstraram desconhecer as estratégias linguísticas desse fenômeno linguístico, o que corresponde a quase metade da turma.

Seguindo, ainda, a prescrição prevista na sequência "a", transcrevemos dois textos escritos, pertencentes ao corpus. Escolhemos, para tanto, os textos PED09 e PED28. 
Examinemos como se materializou a "reprodução" do discurso-outro nos textos-aluno, previamente, selecionados. Para ilustrar a descrição prevista na sequência "a", recortamos do conjunto de textos, constituintes do corpus, a configuração textual do aluno, identificado pelo código PED09. É importante revelar que esse aluno tem 15 anos de idade, o que o coloca dentro das expectativas para a série cursada $\left(9^{\circ}\right.$ ano $)$.

\section{Transcrição da PED09}

\begin{tabular}{|c|c|}
\hline 1 & Sou completamente contra à liberação da maconha no \\
\hline 2 & Brasil, pois, a epidemia da droga se constitui no maior \\
\hline 3 & problema de saúde pública e de segurança no país. \\
\hline 4 & A maconha, nos últimos 200 anos, vem causando verda- \\
\hline 5 & deiras tragedias sociais em todos os locais onde a propria \\
\hline 6 & foi liberada. Pesquisas, no ano de 2014, afirmaram que \\
\hline 7 & possuíam aproximadamente 40 milhões de dependentes \\
\hline 8 & químicos no Brasil, justamente porque a droga era le- \\
\hline 9 & gal e de fácil acesso. A maconha também e letal. Os \\
\hline 10 & riscos de complicações pulmonares e câncer que ela \\
\hline 11 & trás são maiores que os de tabaco. \\
\hline 12 & Com a liberação da maconha, muitas pessoas se- \\
\hline 13 & rão afetadas por esse transtorno. Números irão au- \\
\hline 14 & mentar, tais como: homicídios, violência no trânsito, \\
\hline 15 & suicídios, violência doméstica, dentre outros. \\
\hline 16 & Por todos esses motivos, deve, sim, proibir o uso \\
\hline 17 & da devida droga e haver mais rigor contra a \\
\hline 18 & maconha e outras drogas ilícitas. \\
\hline 21 & Nazareno Duarte. \\
\hline
\end{tabular}

Fonte: Guimarães (2016).

O aluno que escreveu o texto PED09, fê-lo, como se apresenta acima, em 19 (dezenove) linhas escritas, todavia, destas, apenas 5 (cinco) podem ser indicadas como de sua "propriedade". Sobre isso, podemos inferir que 14 (quatorze) linhas são recortes dos textos-fonte. Na verdade, esse "remendo" foi reproduzido quase que exclusivamente do Texto-fonte 2. Dos 15 (quinze) parágrafos do texto Legalização das drogas não é caminho para diminuir violência, o aluno PED09 retalhou a estrutura sintática dos parágrafos 1, 2, 3, 5, 11 e 14, o que nos faz pressupor que o movimento foi feito de forma linear, sequencial, progressiva.

A seguir, demonstramos a configuração textual do aluno que escreveu a PED29. 
Vejamos:

Transcrição da PED29

\begin{tabular}{|l|l|}
\hline 01 & Na minha opinião a maconha tem que manter a \\
\hline 02 & proibição pois o Brasil já não esta prestando, e mais \\
\hline 03 & com a legalização da maconha? Não concordo plena-. \\
\hline 04 & mente. \\
\hline 05 & Como na opinião do Osmar Terra, sou firmemente \\
\hline 06 & contrário á liberação das drogas no Brasil. Falo como médi- \\
\hline 07 & co, estudioso do assunto, e gestor de saúde publica \\
\hline 08 & por oito anos, como secretário de saúde do Rio Gra- \\
\hline 09 & nde d Sul e presidente do Conselho Nacional de \\
\hline 10 & Secretários Estaduais de Saúde. \\
\hline 11 & A experiência me permite afimar que a epedemia \\
\hline 12 & das drogas se constitui no maior problema de saú- \\
\hline 13 & de pública e de segurança no pais. Com a liberação, \\
\hline 14 & aumentará o número de dependentes quimicos das dro- \\
\hline 15 & gas. \\
\hline 16 & Nos últimos 200 anos já tivemos verdadeiras tragédias \\
\hline 17 & sociais em todos os locais onde as drogas foram \\
\hline 18 & liberadas. Junto com o aumento de transtornos men- \\
\hline 19 & tais decorrentes da dependência, aumentaram os \\
\hline 20 & Problemas sociais, de segurança e de saúde. Sem \\
\hline 21 & falar na destruição de milhões de familia, devas- \\
\hline 22 & tadas quando um de seus membros se torna depen- \\
\hline 23 & dente, quem tem um caso de dependência na fami- \\
\hline 24 & lia sabe do que falo. \\
\hline 26 & \\
\hline
\end{tabular}

Fonte:Guimarães (2016).

O aluno que produziu o texto PED29, fê-lo, como exposto anteriormente, em 25 (vinte e cinco) linhas escritas, todavia, destas, em torno de 5 (cinco) podem caracterizar como sendo de seu "domínio" linguístico. Dado o relevado, podemos pressupor que 19 (dezenove) linhas indicam a presença de discursos oriundos dos textos-fonte. De fato, essa "incorporação" é reprodução quase que exclusiva do Texto-fonte 2, tal qual o aluno PED09. Dos 15 (quinze) parágrafos estruturantes texto Legalização das drogas não é caminho para diminuir violência, o aluno PED29 selecionou a estrutura sintática, parcial ou totalmente, dos parágrafos 1,2 e 3.

Dando prosseguimento à descrição do corpus, expomos, neste momento, as situações linguísticas que tenham materializados elementos da língua indiciadores do uso, reflexivo ou não, de pelo menos uma construção sintática prototípica ou variacional de 
representação do discurso-outro, prescrita na sequência "b".

Nesse corpus foi possível identificar 26 (vinte e seis) ocorrências que apresentam marcas linguísticas indiciadoras dos modos de citar, ou seja, os estudantes fizeram uso de alguma estrutura linguística indicadora de gerenciamento do discurso alheio. Essa conjuntura será descrita analiticamente nos quadros sucedâneos. Do total de alunos (31) que participaram da aula, 15 (quinze), reflexivamente ou não, recorreram a pelo menos uma marca linguística que pode apontar a utilização dos modos de citar.

Seguindo o roteiro planejado, apresentamos, no esquema abaixo, os elementos linguísticos indicadores do uso dos modos de citar, conforme descrito na sequência " $b$ ". Para orientar o entendimento dos dados, construímos um panorama que apresenta minuciosamente esse fenômeno da língua, com foco na forma sintática do discurso relatado e no tipo de ocorrência, ora uma construção prototípica, ora uma variação/reformulação do modo de citar. Observemos, então, o quadro representativo:

Quadro 2: Resultado do levantamento obtido

\begin{tabular}{|c|c|c|}
\hline $\begin{array}{l}\text { Código } \\
\text { Aluno }\end{array}$ & $\begin{array}{c}\text { Forma(s) sintática(s) que indicie(m) a utilização do discurso } \\
\text { relatado }\end{array}$ & $\begin{array}{c}\text { Tipo de } \\
\text { ocorrência }\end{array}$ \\
\hline \multirow{2}{*}{ PED01 } & $\begin{array}{l}\text { Modalização em Discurso Segundo: modalizador "como" + verbo } \\
\text { dicendi + referência da autoria + citação isolada por aspas. }\end{array}$ & Variação \\
\hline & $\begin{array}{l}\text { Discurso Indireto: referência da autoria + pronome pessoal "ele" + } \\
\text { verbo dicendi + interpretação do discurso citado. }\end{array}$ & Variação \\
\hline \multirow{2}{*}{ PED 02} & $\begin{array}{l}\text { Discurso Direto: verbo dicendi + referência de autoria + citação } \\
\text { isolada por aspas. }\end{array}$ & Prototípica \\
\hline & $\begin{array}{l}\text { Discurso Direto: referência de autoria + verbo dicendi + citação } \\
\text { isolada por aspas. }\end{array}$ & Prototípica \\
\hline \multirow{2}{*}{ PED 03} & $\begin{array}{l}\text { Discurso direto: citação isolada por aspas no } 1^{\circ} \text { parágrafo; verbo } \\
\text { dicendi }+ \text { referência de autoria no } 2^{\circ} \text {. }\end{array}$ & Variação \\
\hline & \begin{tabular}{|l}
$\begin{array}{l}\text { Discurso direto: citação isolada por aspas no } 4^{\circ} \text { parágrafo; } \\
\text { referência de autoria no } 5^{\circ} \text {. }\end{array}$ \\
\end{tabular} & Variação \\
\hline PED 04 & $\begin{array}{l}\text { Modalização em Discurso Segundo: interpretação de um discurso } \\
\text { segundo, resgatado pela autoria do texto-fonte, mas sem indicação } \\
\text { dessa referência. }\end{array}$ & Variação \\
\hline PED 05 & $\begin{array}{l}\text { Modalização em Discurso Segundo: modalizador de discurso + } \\
\text { referência de autoria + citação isolada por aspas. }\end{array}$ & Prototípica \\
\hline \multirow{2}{*}{ PED 06} & Discurso Direto: referência de autoria + citação isolada por aspas. & Variação \\
\hline & Discurso Direto: referência de autoria + citação isolada por aspas. & Variação \\
\hline PED 07 & $\begin{array}{l}\text { Discurso Indireto: verbo dicendi + referência de autoria intercalada } \\
+ \text { conjunção integrante "que" + interpretação do discurso citado. }\end{array}$ & Prototípica \\
\hline PED 10 & $\begin{array}{l}\text { Discurso Direto: citação isolada por aspas; ausência de referência de } \\
\text { autoria e de verbo dicendi. }\end{array}$ & Variação \\
\hline
\end{tabular}




\begin{tabular}{|c|c|c|}
\hline \multirow{2}{*}{ PED 11} & $\begin{array}{l}\text { Discurso Indireto: referência de autoria + verbo dicendi }+ \\
\text { conjunção integrante "que" + interpretação do discurso citado. }\end{array}$ & Prototípica \\
\hline & $\begin{array}{l}\text { Discurso Direto: referência de autoria + verbo dicendi + dois pontos } \\
+ \text { citação isolada por aspas. }\end{array}$ & Prototípica \\
\hline \multirow{3}{*}{ PED 12} & $\begin{array}{l}\text { Discurso Indireto: referência de autoria via pronome pessoal + } \\
\text { verbo dicendi + conjunção integrante "que" }+ \text { interpretação de } \\
\text { discurso citado. }\end{array}$ & Prototípica \\
\hline & $\begin{array}{l}\text { Modalização em Discurso Segundo: modalizador de discurso + } \\
\text { verbo dicendi + referência de autoria + interpretação de discurso } \\
\text { citado. }\end{array}$ & Prototípica \\
\hline & $\begin{array}{l}\text { Modalização em Discurso Segundo: modalizador de discurso + } \\
\text { verbo dicendi + referência de autoria + interpretação de discurso } \\
\text { citado. }\end{array}$ & Prototípica \\
\hline \multirow{3}{*}{ PED 23} & $\begin{array}{l}\text { Modalização em Discurso Segundo: modalizador de discurso + } \\
\text { verbo dicendi + referência de autoria + referência de autoria via } \\
\text { pronome pessoal (duplo sujeito) }+ \text { interpretação de discurso citado. }\end{array}$ & Variação \\
\hline & $\begin{array}{l}\text { Discurso Indireto: referência de autoria + referência de autoria via } \\
\text { pronome pessoal (duplo sujeito) + verbo dicendi }+ \text { interpretação de } \\
\text { discurso citado. }\end{array}$ & Variação \\
\hline & $\begin{array}{l}\begin{array}{l}\text { Discurso Indireto: referência de autoria + verbo dicendi + } \\
\text { conjunção integrante "que" + interpretação de discurso citado. }\end{array} \\
\end{array}$ & Prototípica \\
\hline \multirow{2}{*}{ PED 24} & $\begin{array}{l}\text { Discurso Direto: referência de autoria + verbo dicendi + conjunção } \\
\text { integrante "que" + citação direta sem o uso de aspas. }\end{array}$ & Variação \\
\hline & \begin{tabular}{|l}
$\begin{array}{l}\text { Discurso Indireto: referência de autoria + verbo dicendi }+ \\
\text { conjunção integrante "que" + interpretação de discurso citado. }\end{array}$ \\
\end{tabular} & Prototípica \\
\hline PED 29 & $\begin{array}{l}\text { Modalização em Discurso Segundo: modalizador de discurso + } \\
\text { referência de autoria + + indício de verbo implícito + citação direta } \\
\text { sem o uso de aspas. }\end{array}$ & Variação \\
\hline PED 30 & $\begin{array}{l}\text { Discurso Direto: pronome pessoal retomador de autoria + verbo } \\
\text { dicendi + citação direta sem o uso de aspas. }\end{array}$ & Variação \\
\hline \multirow{2}{*}{ PED 31} & Discurso Direto: citação isolada por aspas + referência de autoria. & Variação \\
\hline & Discurso Direto: citação isolada por aspas + referência de autoria. & Variação \\
\hline
\end{tabular}

Fonte:Guimarães (2016).

Em síntese, o quadro evidencia a presença de indícios de uso das formas de citar, conforme descrito: 3 (três) ocorrências prototípicas e 9 (nove) variações do discurso citado direto; 5 (cinco) ocorrências prototípicas e 2 (duas) variações do discurso citado indireto; e 3 (três) ocorrências prototípicas e 4 (quatro) variacionais da utilização da modalização em discurso segundo, totalizando 26 eventuais marcas linguísticas de remissão do discursooutro.

Abaixo, o quadro mostra o modo de citar, materializado nas 26 (vinte e seis) ocorrências, de acordo com o prescrito na sequência "c", isto é, copilar quais as formas de gerenciamento do discurso-outro predominam nos textos observados na sequência " $b$ ". 
Vejamos:

Quadro 3: Resumo do levantamento obtido

\begin{tabular}{|c|c|c|c|c|c|}
\hline \multirow{4}{*}{ Sequência } & \multicolumn{5}{|c|}{ Quantidade de ocorrências } \\
\hline & $\begin{array}{l}\text { "Porta- } \\
\text { voz" }\end{array}$ & "Interpretação" & Form & híbrida & $\begin{array}{l}\text { Forma } \\
\text { híbrida }\end{array}$ \\
\hline & \multirow{2}{*}{$\begin{array}{l}\text { Discurso } \\
\text { Direto }\end{array}$} & \multirow{2}{*}{ Discurso Indireto } & \multicolumn{2}{|c|}{$\begin{array}{c}\text { Modalização em } \\
\text { Discurso Segundo }\end{array}$} & \multirow{2}{*}{$\begin{array}{l}\text { Ilha } \\
\text { Textual }\end{array}$} \\
\hline & & & $\begin{array}{l}\text { Forma } \\
\text { Direta }\end{array}$ & $\begin{array}{c}\text { Forma } \\
\text { Indireta }\end{array}$ & \\
\hline $\begin{array}{l}\text { c) Formas de remissão } \\
\text { do discurso-outro }\end{array}$ & 12 & 7 & 3 & 4 & $\varnothing$ \\
\hline TOTAL & \multicolumn{5}{|c|}{26} \\
\hline
\end{tabular}

Fonte: Guimarães (2016).

O quadro explicita que há uma tendência para o emprego do discurso citado direto. Essa preferência se justifica pela quantidade de evidências em que o aluno isolou as vozes alheias por meio do emprego de aspas. Para Maingueneau (2001, p. 150), "em geral, a impressa popular prefere o discurso direto ao DI.”. Assim, é possível que o contato com textos dessa esfera social faça com que o aluno utilize esse estilo na produção do seu texto. Outro ponto favorável para essa ocorrência é o fato de a proposta de produção escrita ser antecipada pela leitura de textos da esfera jornalística. Maingueneau (2001, p.150) justifica que "para um público leitor popular, o jornalista privilegia a narração, uma relação mais imediata com o vivido, as palavras mesmas das pessoas, como se o leitor estivesse presente na situação".

Esse resultado também comprova que uma parcela significativa dos alunos da turma já usa as formas de gerenciamento do discurso de outrem. No entanto, esse ponto nos fez pensar na forma como o aluno usou os modos de citar: de forma reflexiva, intencional ou apenas por "imitar" outros autores. Hipoteticamente, podemos inferir que esse "uso" nasceu do contato que o aluno tem com a mídia virtual. Além disso, os textos usados em sala traziam marcas de remissão das vozes alheias, o que pode ter "motivado" a presença de marcas que indiciem a utilização das formas sintáticas do discurso-outro.

Dessa forma, na escrituração dos textos, os alunos demonstraram indícios de "propriedade" linguístico-discursiva, mesmo que, ainda, principiante no uso de pelo menos uma das formas (ou variações) sintáticas do discurso relatado. 
Com a finalidade de expor um retrato, via exposição de texto, que comprove o critério mencionado na sequência " $b$ ", isolamos do conjunto de produtos textuais, oriundo do corpus, as tessituras textuais dos alunos, identificados pelos códigos PED11 e PED01, respectivamente, transcritos. Esses alunos têm 15 anos e se encontram matriculados na série esperada ( $9^{\circ}$ ano). No quadro abaixo, podemos entender como essa ocorrência se manifestou, primeiro, o texto PED11:

\section{Texto-aluno PED11}

\begin{tabular}{|c|c|}
\hline 1 & As drogas além de prejudicar o convívio social e familiar \\
\hline 2 & trás problemas como, destrói vidas; será que deve ser \\
\hline 3 & mesmo legalizada? \\
\hline 4 & O Deputado Jean Wyllys pensa que se a annabis for legalizada \\
\hline 5 & poderia até acabar com guerra traficantes passariam a \\
\hline 6 & vende-lás legalmente, já o deputado Osmar que é mas \\
\hline 7 & entendido do assunto diz: "Sou firmemente contrário á libe- \\
\hline 8 & ração das drogas no Brasil". Na minha opinião como aluno \\
\hline 9 & considero um absurdo até levantar essa hipótese eu sei \\
\hline 10 & que cada um tem direito de expressão fazer o que quiser \\
\hline 11 & e tal, nas não acho um caminho certo para acabar com \\
\hline 12 & essa epidemia, só aumentaria mais os usuários e \\
\hline 13 & ficaria uma loucura, qualquer um poderia comprar \\
\hline 14 & ate mesmo um adolescente ficária muito fácil por \\
\hline 15 & isso não acho uma idéia sensata. O mundo \\
\hline 16 & já esta do jeito que tá crianças hoje com menos \\
\hline 17 & de 10 anos já são traficantes e usuários de drogas \\
\hline 18 & sem a legalização imagine com passe livre. \\
\hline 21 & \\
\hline
\end{tabular}

Fonte: Guimarães (2016).

Vale salientar que alguns alunos apresentaram marcas gráficas (aspas, dois$\operatorname{pontos}^{7}$ ), verbos de elocução, conjunção integrantes “que", o que indicia um conhecimento desses mecanismos linguísticos de apresentar vozes alheias. O texto PED11 apresenta dois indícios de uso de gerenciamento do discurso de outrem. Nas linhas 4 a 6 , a marca linguística se aproxima do discurso citado indireto, apresentando referência de autoria

\footnotetext{
${ }^{7}$ Esse sinal gráfico apareceu em alguns textos dos alunos independentemente de terem sido orientados a escrever um texto predominante argumentativo, em que esse fenômeno linguístico não é tão recorrente, esse uso, talvez, seja justificado pelo contato bastante regular que os alunos têm (ou tiveram) com textos do
} 
(“Deputado Jean Wyllys"), acompanhado de verbo dicendi ("pensa”), concatenado pela conjunção integrante "que", seguido da tradução, interpretação do discurso citado, configurando-se numa ocorrência prototípica.

Nas linhas 6 a 8, o fenômeno linguístico se assemelha ao discurso citado direto, expondo menção da autoria (“deputado Osmar"), verbo dicendi (“diz”), sequenciado de sinal gráfico (dois-pontos), seguido de citação isolada por aspas (sinal gráfico), representando uma ocorrência prototípica.

A seguir, expomos como o discurso de outrem se evidencia no texto PED01:

\section{Texto-aluno PED01}

\begin{tabular}{|c|c|}
\hline 01 & A maconha pode chegar a matar, não somente \\
\hline 02 & a maconha, como as outras drogas. como fala no texto \\
\hline 03 & de Osmar Terra, "A maconha também é letal. Os riscos \\
\hline 04 & de complicações pulmonares e câncer que ela traz são \\
\hline 05 & maiores que os do tabaco". \\
\hline 06 & No texto de Jean Wyllys ele propõe uma anistia \\
\hline 07 & geral para todas as pessoas presas, processando ou in- \\
\hline 08 & dicados por tráficos de maconha, exceto para policiais \\
\hline 09 & e para aqueles que tinham praticado outros crimes". \\
\hline 10 & Diversas pessoas chegam a morrer, por causa de \\
\hline 11 & qualquer droga, até mesmo o cigarro, que é o mais \\
\hline 12 & aceito, essa situação deve ser tratada, eu sou \\
\hline 13 & totalmente contrar a legalização da maconha, não \\
\hline 14 & é certo o que os jovens de hoje em dia faz, ficar \\
\hline 15 & emgrupanho uma "boca”, como são falado por ele- \\
\hline 16 & s. que isso venha ser tratado. \\
\hline 30 & Pseudônimo: Nazareno Duarte \\
\hline
\end{tabular}

Fonte: Guimarães (2016).

O texto PED01 apresenta, nas linhas 3 a 5, características linguísticas que o aproxima da modalização discursiva, optando pelo discurso direto. A sintaxe é iniciada por um modalizador (“como"), depois pela presença de verbo dicendi ("fala"), seguido de referência de autoria, mais citação isolada por aspas, configurando numa variante.

Já nas linhas 6 a 9, a materialização discursiva parece indicar a utilização do discurso citado indireto, pois a sentença é iniciada com uma referência à autoria do discurso, repetição de autoria, por meio de pronome pessoal ("ele"), verbo dicendi 
("propõe"), seguido de interpretação do discurso citado, porém o aluno finaliza esse enunciado com aspas, o que não se justifica, pois se faz uma tradução do discurso-fonte.

Outro fenômeno linguístico presente nas tessituras textuais em análise diz respeito a indicadores de resposta direta aos discursos dos interlocutores (Jean Wyllys e Osmar Terra). No total, há 11 (onze) elementos linguísticos indiciadores desse mecanismo linguístico. Diante dessa constatação, tivemos a preocupação de explicitar essa estratégia linguística. O texto PED02 apresenta elementos linguísticos indicadores de resposta aos textos-fonte. Observem como isso se materializou no texto:

\section{Texto-aluno PED02}

\begin{tabular}{|l|l|}
\hline 02 & Na minha opnião, a cannabis não seria necessário, \\
\hline 03 & legalização, até porque maconha também é droga, \\
\hline 04 & e drogas trazem muitas consequências. \\
\hline 05 & As drogas atingem principalmente o "público \\
\hline 06 & alvo jovem” que são considerados como os mais \\
\hline 07 & imaturos e que não pensam nas consequências \\
\hline 08 & antes de fazer, os jovens de hoje estão começando \\
\hline 09 & pela cannabis e quando se ver estão queimando \\
\hline 10 & pedra, cheirando cola, fazendo coisas que \\
\hline 11 & não devem. \\
\hline 12 & Como diz o Jean Willys (deputado federal - psol) “e a pesso- \\
\hline 13 & a pode ir parar em presídios superlotados, que são verdade- \\
\hline 14 & iros infernos e escolas do crime” ele pode estár certo \\
\hline 15 & nesta parte, mas como queremos os jovens futuramen- \\
\hline 16 & te? como viciados e retardados? ou como dependen- \\
\hline 17 & tes e sábios? não queremos destruir o Brasil ainda \\
\hline 18 & mais, deve aver outro jeito. \\
\hline 19 & Mas já concordando com o Osmar terra (deputado \\
\hline 20 & federal - PMDB) ele diz “Com á liberação aumentará o \\
\hline 21 & número de dependentes químicos das drogas”, não \\
\hline 22 & Podemos deixar que a “Cannabis” vençam os nossos \\
\hline 23 & jovens, pois isso pode até atrapalhar os estudos e \\
\hline 24 & atrapalhando os estudos estará também atrapalha- \\
\hline 25 & ndo o futuro. \\
\hline
\end{tabular}

Fonte: Guimarães (2016).

$\mathrm{O}$ aluno PED02 organizou seu texto em 4 (quatro) parágrafos. No primeiro, o aluno já apresenta seu posicionamento acompanhado de uma justificativa, provavelmente, respondendo à pergunta feita na proposta de produção textual escrita (Maconha: legalizar ou manter a proibição?). No segundo, destaca-se que os jovens são os possíveis usuários 
da maconha, sobretudo, por estarem mais suscetíveis à droga e por ainda não serem maduros, estarem em um processo de formação social.

Em seguida, no terceiro parágrafo, recorre-se ao discurso, via citação direta isolada por aspas, de Jean Wyllys, do PSOL, considerando que o deputado "pode estár certo nesta parte", o que nos faz inferir que o aluno responde ao político. Essa inferência é evidenciada na sequência da construção sintática, já que o aluno elabora perguntas retóricas e já as responde no encadeamento parafrástico.

O último parágrafo é iniciado com um elemento coesivo indicador de oposição (“mas”) e de uma palavra de realce (“já”). Esse contraste é revelado na progressão da sentença, principalmente, ao explicitar sua filiação ("Mas já concordando...") com o deputado Osmar Terra. Sobre essa construção, ainda, podemos depreender uma refutação ao discurso de Jean Wyllys, pois ao escrever que já concorda com Osmar Terra, também contradiz "as palavras" do político psolista.

Além dessa expectativa, os produtos gerados para esta pesquisa demonstram que 06 (seis) alunos utilizaram os textos-base como fonte implícita.As produções escritas trazem uma forma de citar sem a presença de elementos linguísticos. $\mathrm{O}$ aluno escreve seu texto a partir das ideias presentes nos textos da coletânea, contudo, apenas os utiliza como uma "fonte implícita", o que, muitas vezes, é comum nos contextos escolares (pois, não raro, os professores "solicitam" que os alunos reescrevam textos usando as próprias palavras). No universo acadêmico, chamamos essa estratégia linguística de paráfrase ${ }^{8}$.

Para ilustrar esse fenômeno, transcrevemos o texto do aluno PED18. A saber:

Texto-aluno PED18

\begin{tabular}{|l|l|}
\hline 01 & \multicolumn{1}{|c|}{ Sociedade afavor ou contra? } \\
\hline 02 & A maconha ou "cannabis" é uma substância ilicita, também con- \\
\hline 03 & siderado como droga e seu uso pode ser prejudicial de acordo com \\
\hline 04 & a forma de uso. \\
\hline 05 & A legalização da maconha alem de ser uma forma de liberdade in- \\
\hline 06 & dividual é uma ideia contra o fim da guerra e acabar com o tra- \\
\hline 07 & fico “escondido", que muitas vezes é causa de mortes ou motivo \\
\hline 08 & dos adolescente fugirem por não ter a aprovação dos pais de ser \\
\hline
\end{tabular}

\footnotetext{
${ }^{8}$ Entendemos, aqui, a paráfrase como sendo a "[...] relação entre um enunciado ou texto-fonte e sua (s) reformulação(ões) efetiva(s) numa situação dada (dimensão "sintagmática" da cadeia do discurso), mas é também uma relação entre todos os enunciados virtualmente equivalentes na língua (dimensão "paradigmática" do sistema da língua)" (FUCHS, 2012, p. 129).
} 


\begin{tabular}{|l|l|}
\hline 09 & um dependente quimico. \\
\hline 10 & A consequência do ato da guerra muitas vezes é por grupos ri- \\
\hline 11 & vais que querem adiquirir mais e entram em confronto e mui- \\
\hline 12 & tos jovens acabam morrendo, e a legalização iria intenrroper \\
\hline 13 & com a guerras. \\
\hline 14 & Mas olhando por outro lado a legalização seria uma das prin- \\
\hline 15 & cipaiseat causas de epidemia, e auto consumo exagerado, pois \\
\hline 16 & qualquer um de velho a criança teria fácil acesso, alem de "bocas de \\
\hline 17 & fumos" ser mas comuns e contaminando que estivesse ou mora- \\
\hline 18 & sse próximo. \\
\hline 19 & Isso influênceria muito a sociedade tanto nas ruas, como es- \\
\hline 20 & colas ou pontos, pois seria muito fácil compra, ingirexageradamen- \\
\hline 21 & te e acabar tendo sério pl problemastinuar \\
\hline 22 & Por isso \\
\hline 23 & proibida, e seu uso ilicito, pois seria prejudicial a mui- \\
\hline 24 & ta gente, porque que se evolve sabe o que acontece e onde is- \\
\hline 25 & so pode levar, e para melhorar deveriamo combate mais esse pro- \\
\hline 26 & blema extinguindo cada vez mais essas substância de usuários \\
\hline 27 & inresponsáveis. \\
\hline 30 & \\
\hline
\end{tabular}

Fonte: Guimarães (2016).

O aluno PED18 parece ter construído seu texto

[...] no plano do discurso, como uma atividade efetiva de reformulação pela qual o locutor [no caso, o aluno] restaura (bem ou mal, na totalidade ou em parte, fielmente ou não) o conteúdo de um texto-fonte sob a forma de um texto-secundo" (FUCHS, 2012, p. 133, grifo nosso).

O segundo e terceiro parágrafos indicam que o aluno elaborou uma espécie de tradução ou interpretação das ideias defendidas pelo autor do Texto 1 (Maconha deve ser legalizada, e traficantes da droga, anistiados), principalmente, pela presença (explícita) de marcas linguísticas oriundas desse texto-fonte: "forma de liberdade individual", "o fim da guerra", "e acabar com o trafico". Essa releitura, materializada na escrita do aluno, também toma como fonte implícita os princípios defendidos por Osmar Terra na escrita do Texto 2 (Legalização das drogas não é caminho para diminuir a violência), provavelmente, podendo ser recuperada no texto-aluno por meio da palavra "epidemia" (fortemente usada pelo autor do Texto-fonte 2). Todavia, não é possível "rotular" esse jogo linguístico como reprodução, simplesmente, porque a sintaxe configura-se como um "novo" estilo de escrita, diferente do modo dizer do texto-fonte. Há, portanto, 


\section{REVISTA $\mathbf{X}$}

reedição/atualização discursiva.

A esse respeito, cabe-nos pontuar que a forma de citar depende do regime de autoria dos textos citados, e, também, dos textos citantes, ou seja, há textos que, por um sistema da cultura letrada, constituem-se como "fonte" para outros (e, por que não, "novos") textos, sobretudo, os do conhecimento científico-acadêmico.

A esse respeito,

O discurso retórico, diferentemente do discurso literário, pela própria natureza da sua orientação, não é tão livre na sua maneira de tratar as palavras de outrem. Ele tem, de forma inerente, um sentimento agudo dos direitos de propriedade da palavra e uma preocupação exagerada com a autenticidade (BAKHTIN, 2014, p. 159).

Nesse mesmo sentido, diferentes desses, os textos ligados ao universo da música, por exemplo, não seguem, literalmente, a essa "sistematização". Nestes, não há obrigatoriedade na marcação ou referenciação das vozes alheias. Isso não isenta sua presença, no entanto, não há uma "cobrança" cultural, pelo contrário, torna-se um "estilo" de escrita. Talvez, essa inserção seja por conta do universo da criação/recriação a qual esses textos se apresentam socialmente.

\section{CONSIDERAÇÕES FINAIS}

O foco deste artigo é refletir sobre os modos de escrita de alunos ao término da segunda etapa da educação básica, sobretudo, no que tange ao emprego das formas sintáticas do discurso relato, materializadas em textos escritos em sala de aula.Contribuindo no fazer ciência, acreditamos que há uma tendência, nas unidades escolares, provavelmente favorecida pela disseminação de textos na internet, de o aluno reproduzir o discurso alheio pautado no "ritual" contemporâneo do "copiar/colar", o que corrobora com estudos já desenvolvidos, consoante já apontaram as pesquisadoras Fabiano-Campos e Bernardes (2014) e Lima e Amorim (2014). Essa constatação coloca-se como mais um desafio no processo de ensino e de aprendizagem da escrita na escola.

Não que haja algo incomum em reportar o já dito, o problema consiste em tornarse "proprietário", indevidamente, do discurso citado. Esse rito caracteriza-se quando o aluno, ao escrever textos, toma como seu, sem indicativo de referência, um discurso já 
veiculado socialmente. $\mathrm{O}$ aluno tende a reproduzir os discursos que circulam socialmente, ou seja, aquele que escreve copia o discurso-outro sem indicar o autor-fonte. Defendemos a ideia de que o ato de escrever seja um processo de construção/reconstrução do dizer e do já dito. O texto ao ser construído/reconstruído, numa situação comunicativa distinta da do texto-fonte, pode, então, ressignificar, ganhar sentido "singular", atender a uma nova intenção comunicativa.

Porém, o diagnóstico ${ }^{9}$ mostra que os alunos se sentem confortáveis em validar sua voz por meio da palavra do outro, sem nem se preocupar em reproduzi-la; os alunos já ensaiam um uso dessas marcas e, inclusive, reformulam sentenças de forma interpretativa, ou seja, colaboram com a discussão feita. Esses apontamentos validam a hipótese levantada.

Portanto, esses resultados apontam para o surgimento de inquietações outras. Levando em consideração que os textos em análise refletem um tratamento didático proposto pelos Parâmetros Curriculares Nacionais de Língua Portuguesa (PCNLP), sobretudo no que tange à adoção dos gêneros do discurso como objetos de ensino, de que modo essa guinada teórico-metodológica perpassa a prática da escrita na sala de aula? O que tem levado o aluno a reproduzir de forma costumaz o discurso alheio? Seria tãosomente uma forma de validar a voz experiente do citado em detrimento do discurso citante ou simplesmente uma dificuldade em saber gerenciar as marcas sintáticas do discurso relatado?

Essas questões carecem de aprofundamento teórico-metodológico, uma vez que o levantamento aponta que "desenvolver", nos alunos, o "pleno domínio da escrita" ainda é um desafio a se superar no ensino brasileiro e que nem passem pelo clichê competência e habilidades, ideias-chave com um fim em si mesmas, entendidas como unidade, mas passa por entender que escrever é um processo em constante mudança, o que requer um aprender cotidianamente.

Esperamos com essas inquietudes despertar a emergência de outras pesquisas que possam contribuir para a construção do conhecimento, quer seja no sentido de apontar

\footnotetext{
${ }^{9}$ É importante destacar que os textos analisados são resultados de uma proposta de produção textual escrita aplicada em sala de aula a fim de averiguar o modo pelos quais os alunos mobilizam as formas sintáticas de discurso relatado. Como se tratava de uma atividade diagnóstica, não houve intervenção pedagógica por parte do professor. Também não se inibiu o diálogo entre os alunos.
} 


\section{REVISTA $\mathbf{X}$}

novas diretrizes epistemológicas, quer seja na ideia de revisão dos preceitos pedagógicos atuais ou ainda na reformulação das epistemes já em trânsito no cenário brasileiro.

\section{REFERÊNCIAS}

AUTHIER-REVUZ, J. Heterogeneidade(s) enunciativa(s). Cadernos de Estudos Linguísticos. Campinas, n.19, p.25-42, jul./dez., 1990. Disponível em: $<$ https://periodicos.sbu.unicamp.br/ojs/index.php/cel/article/view/8636824>. Acesso em: 15 mai. 2016.

AUTHIER-REVUZ, J. Nos riscos da alusão. Portal de periódicos da UFPE, 2000, p. 0946. Disponível em: <www.repositorios.ufpe.br/revistas/index.php/INV/article/viewFile /1468/1142>. Acesso em: 5 nov. 2016.

AUTHIER-REVUZ, J. Entre a transparência e a opacidade:um estudo enunciativo do sentido. Porto Alegre: EDIPUCRS, 2004.

AUTHIER-REVUZ, J. A representação do discurso outro: um campo multiplamente heterogêneo. Calidoscópio, v.6, n.2, p.107-119, mai/ago., 2008. Disponível em: $<$ http://revistas.unisinos.br/index.php/calidoscopio/article/view/5252/2506 >. Acesso em: 2 jun. 2016.

BAKHTIN, M.; VOLOCHÍNOV, V. Marxismo e filosofia da linguagem. 16.ed. São Paulo: Hucitec, 2014.

FABIANO-CAMPOS, S.; BERNARDES, J. Que livro didático é esse? Mecanismos de controle no ensino da escrita. In: FABIANO-CAMPOS, S.; BARZOTTO, V. H. (Org.). Ensino de leitura e da escrita. Natal: EDUFRN, 2014, p. 65-85.

FUCHS, C. A paráfrase linguística - equivalência, sinonímia ou reformulação? Cadernos de Estudos Lingüísticos, Campinas, SP, v.8, p.129-134, 2012. Disponível em: $<$ https://periodicos.sbu.unicamp.br/ojs/index.php/cel/article/view/8636744> $>$. Acesso em: 4 mai. 2016.

GUIMARÃES, G. B. Da reprodução à produção textual: a escrita na sala de aula. Dissertação (mestrado) - Universidade Federal do Rio Grande do Norte, Centro de Ciências Humanas, Letras e Artes, Programa de Mestrado Profissional em Letras, Natal, 2016. Disponível em: <https://repositorio.ufrn.br/jspui/handle/123456789/24324>. Acesso em: 1 jun. 2020.

LIMA, M. H. A.; AMORIM, C. S. O ritual escolar do "CRTL+C" (copiar) e "CRTL+V" (colar): reflexões para o ensino de língua portuguesa. In: FABIANO-CAMPOS, S.; BARZOTTO, V. H. (Org.). Ensino de leitura e da escrita. Natal: EDUFRN, 2014, p. 165193. 
MAINGUENEAU, Dominique. Análise de textos de comunicação. São Paulo: Cortez, 2001.

Recebido em: 01 jul. 2020. Aceito em: 14 ago. 2020. 